Louisiana State University

LSU Digital Commons

Faculty Publications

Department of Chemistry

$3-12-2020$

\title{
Molecular structure, chemical exchange, and conductivity mechanism of high concentration litfsi electrolytes
}

Susith R. Galle Kankanamge

Louisiana State University

Daniel G. Kuroda

Louisiana State University

Follow this and additional works at: https://digitalcommons.Isu.edu/chemistry_pubs

\section{Recommended Citation}

Galle Kankanamge, S., \& Kuroda, D. (2020). Molecular structure, chemical exchange, and conductivity mechanism of high concentration litfsi electrolytes. Journal of Physical Chemistry B, 124 (10), 1965-1977. https://doi.org/10.1021/acs.jpcb.9b10795

This Article is brought to you for free and open access by the Department of Chemistry at LSU Digital Commons. It has been accepted for inclusion in Faculty Publications by an authorized administrator of LSU Digital Commons.

For more information, please contact ir@lsu.edu. 


\title{
Molecular Structure, Chemical Exchange, and Conductivity Mechanism of High Concentration LiTFSI Electrolytes
}

\author{
Susith R. Galle Kankanamge and Daniel G. Kuroda*
}

Cite This: J. Phys. Chem. B 2020, 124, 1965-1977

Read Online

ABSTRACT: High concentration lithium electrolytes have been found to be good candidates for high energy density and high voltage lithium batteries. Recent studies have shown that limiting the free solvent molecules in the electrolytes prevents the degradation of the battery electrodes. However, the molecular level knowledge of the structure and dynamics of such an electrolyte system is limited, especially for electrolytes based on typical organic carbonates. In this article, the interactions and motions involved in lithium bis(trifluoromethanesulfonyl)imide in carbonyl-containing solvents are investigated using linear and timeresolved vibrational spectroscopies and computational methods.

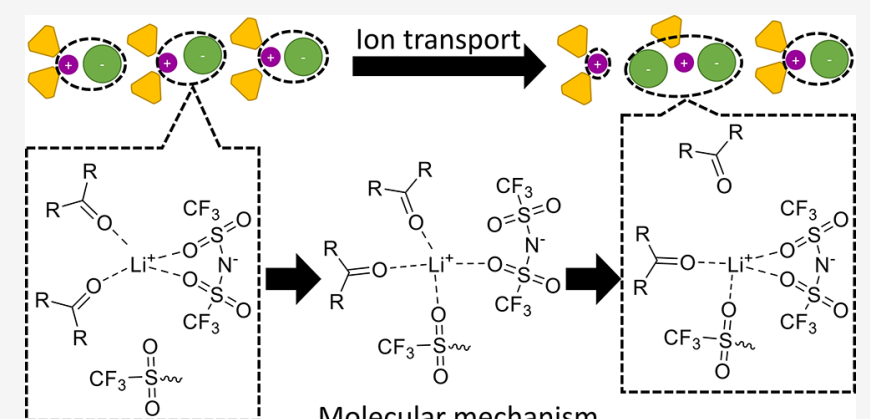

Molecular mechanism Our results suggest that the overall structure and the speciation of the three high concentration electrolytes are similar. However, the cyclic carbonate-based electrolyte presents an additional interaction as a result of dimer formation. Time-resolved studies reveal similar and fast dynamics for the structural motions of solvent molecules in electrolytes composed of linear molecules, while the electrolyte made of cyclic solvent molecules shows slower structural changes as a result of the dimer formation. Additionally, a picosecond time scale process is observed and assigned to the coordination and decoordination of solvent molecules from a lithium-ion solvation shell. This process of solvent exchange is found to be directly correlated to the making and breaking of structures between the lithium-ion and the anion and, consequently, to the conduction mechanism. Overall, our data show that the molecular structure of the solvent does not significantly affect the speciation and distribution of the lithium-ion solvation shells. However, the presence of dimerization between solvent molecules of two neighboring lithium-ions appears to produce a microscopic ordering that it is manifested macroscopically in properties of the electrolyte, such as its viscosity.

\section{INTRODUCTION}

The use of lithium-ion (Li-ion) batteries has gained widespread application in several fields including automobile and energy storage grids due to the high capacity and efficiency of this energy storage technology. ${ }^{1-3}$ However, a battery having high energy density, high voltage, and fast charging rate is yet to be developed. New concepts and modifications to the chemistry of lithium-ion batteries have been introduced to enhance their performance. ${ }^{4-7}$ In particular, there has been a wave of new developments focused on the electrolyte. ${ }^{8-16}$ The electrolyte is one of the main components in a typical electrochemical cell because it is the medium where the charge transport between the electrodes occurs. Moreover, in Li-ion batteries, the electrolyte is responsible for forming the protective interface between the electrolyte and anode. ${ }^{17-21}$ Thus, changes on the electrolyte can significantly affect the properties and performance of the overall battery. Recent studies have shown the feasibility of using high concentration electrolytes for the development of high voltage and high energy density Li-ion batteries. ${ }^{8-10,22-24}$

The concentration of the lithium salt in a conventional Liion battery is typically $\sim 1 \mathrm{M}$ and is primarily dictated by its conductivity. ${ }^{25}$ While increasing the salt concentration decreases the overall conductivity of the electrolyte, a high concentration electrolyte has been shown to possess a better thermal stability than its low concentration counterpart, which is an advantage from a safety perspective. ${ }^{8,26}$ Currently, in commercial Li-ion batteries, solid electrolyte interphase (SEI) is formed by the decomposition of solvent molecules during the first few cycles to prevent the degradation of the electrodes. ${ }^{17-21}$ In particular, it was found that the formation of a stable SEI on the cathode prevents the degradation of the electrodes at high voltage, which occurs due to the presence of excess free solvent molecules in the $\sim 1 \mathrm{M}$ electrolyte. ${ }^{26-29}$ This particular problem is avoided in a high concentration electrolyte because of its limited amount of free solvent

Received: November 18, 2019

Revised: January 13, 2020

Published: February 18, 2020 
molecules prevents the deterioration of the electrodes. ${ }^{8,9,13,26}$ In addition, the large concentration of anions in the high concentration electrolytes contributes to the formation of a stable SEI. ${ }^{10,26}$

High concentration electrolytes are simply made by dissolving lithium salts in high dielectric solvents. ${ }^{8,9}$ Using this recipe, many studies have demonstrated that the molecular characteristics of the anion and solvent are critical for making the electrolytes because they significantly affect the electrolyte properties such as conductivity and electrochemical stability. ${ }^{8,10}$ On the anion side, it is now known that multidentate anions with large charge delocalization are needed. ${ }^{25}$ Two anions that possess all the aforementioned properties are bis(trifluoromethanesulfonyl)imide $\left(\mathrm{TFSI}^{-}\right)$and bis(fluorosulfonyl)imide $\left(\mathrm{FSI}^{-}\right)$. On the solvent side, different solvents have been used for this purpose, and some examples are water, ${ }^{30}$ acetonitrile, ${ }^{22}$ dimethylcarbonate, ${ }^{8}$ and dimethoxyethane. ${ }^{9}$ So far, it has been difficult to predict the macroscopic properties of the electrolyte in terms of its constituents largely due to the lack of a microscopic map detailing the arrangements and interactions occurring in these systems.

The structure and interactions of the molecular components (i.e., solvent, lithium salt ions) in high concentration electrolytes composed of organic solvents have been hardly investigated experimentally ${ }^{31-33}$ and computationally. ${ }^{34}$ Henderson and co-workers derived the structure and interaction of TFSI ${ }^{-}$and $\mathrm{Li}^{+}$in concentrated electrolytes by analyzing the crystal structure of solvates as a function of the solvent molecular structure. ${ }^{35-40}$ These studies revealed the existence of two TFSI $^{-}$conformations (cisoid $\left[\mathrm{C}_{1}\right]$ and transoid $\left[\mathrm{C}_{2}\right]$ ), which only differ by the relative positions of the $-\mathrm{CF}_{3}$ groups. ${ }^{41}$ Moreover, it was found out that the type of the anion conformation governs the coordination with the lithium center. ${ }^{41}$ For example, the transoid conformation is observed for solvent-separated ion pairs, while cisoid conformation is found when $\mathrm{TFSI}^{-}$is directly coordinated to $\mathrm{Li}^{+}$. ${ }^{41}$ Whereas TFSI ${ }^{-}$coordinates to $\mathrm{Li}^{+}$in different ways depending on the structure formed (i.e., solvent-separated ion pairs [SSIP], contact ion pairs $[\mathrm{CIP}]$, and aggregates $[\mathrm{AGG}])$, the solvent coordination to the cation always occurs via the carbonyl oxygen for carbonyl-containing solvents. ${ }^{40}$ Therefore, it has been deduced that the interactions observed in solvates should be maintained in high concentration electrolytes. ${ }^{33,35,42}$ However, the chemical structure of the liquid electrolytes might be significantly different from that of the solid solvate due to the higher number of degrees of freedom in the liquid. Moreover, Watanabe and co-workers previously demonstrated that the structure of the high concentration electrolyte resembles more an ionic liquid than a traditional high concentration solution. ${ }^{42,43}$ Interestingly, while a few studies have been conducted to explore experimentally the structure parameters in high concentration electrolytes, none of them provided direct insights into the structure and dynamics of high concentration electrolytes.

In this work, we investigated the structure and dynamics of high concentration electrolytes compose of LiTFSI salt and one-carbonyl-containing solvents (MP, DMC, or BC) (Scheme 1) using IR spectroscopic and theoretical methods. Our experimental efforts focused on the carbonyl stretch of the solvents because it is a good reporter of both the structure and dynamics. ${ }^{37,44-50}$ Moreover, the use of time-resolved 2DIR spectroscopy allowed us to obtain direct information about the different molecular processes in picosecond time scale
Scheme 1. Chemical Structure of (a) Methyl Propionate (MP), (b) Dimethylcarbonate (DMC), (c) 1,2Butylenecarbonate (BC), (d) Lithium Bis(trifluoromethanesulfonyl)imide (LiTFSI), and (e) Lithium Bis(fluorosulfonyl)imide (LiFSI)
(a)
(b)
$\mathrm{N}^{-1}$
$\mathrm{O}^{\mathrm{O}} \mathrm{H}^{\mathrm{O}}$
(c)
$\left.\Gamma_{0}^{0}\right\rangle=0$
(d) $\mathrm{Oi+}$
(e) $\mathrm{Li}+$

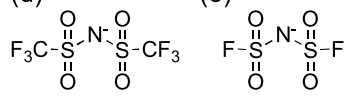

occurring in the different electrolytes. ${ }^{51}$ In addition, the experimental observations were complemented with DFT calculations and classical molecular dynamics simulations to interpret and corroborate our experimental findings.

\section{METHODOLOGY}

Sample Preparation. Lithium bis (trifluoromethylsulfonyl)imide (LiTFSI, $\mathrm{LiN}\left(\mathrm{SO}_{2}\right)_{2}\left(\mathrm{CF}_{3}\right)_{2}$, $>98 \%$ ) was obtained from Alfa Aesar and dried at $130{ }^{\circ} \mathrm{C}$ for $24 \mathrm{~h}$ before use. Methyl propionate ( $\mathrm{MP}, \mathrm{C}_{4} \mathrm{H}_{8} \mathrm{O}_{2}$, >99\%) and dimethyl carbonate (DMC, $\left.\mathrm{C}_{3} \mathrm{H}_{6} \mathrm{O}_{3}, 99 \%\right)$ were obtained from Acros Organics, and 1,2-butylene carbonate (BC, $\mathrm{C}_{5} \mathrm{H}_{8} \mathrm{O}_{3}, 98 \%$ ) was obtained from TCI Chemicals. All solvents were dried with 1-2 mm molecular sieves for $24 \mathrm{~h}$ prior to use. Solutions of LiTFSI in each solvent at 1:1.5, 1:2, and 1:3 $\mathrm{Li}^{+}$:solvent molar ratios were prepared by simply mixing the components inside a $\mathrm{N}_{2}$-filled glovebox at room temperature. After preparation, all the samples contained less than $150 \mathrm{ppm}$ of water.

The cell (Harrick Scientific) for the FTIR experiments consisted of the sample sandwich between a pair of $2 \mathrm{~mm}$ calcium fluoride windows without a spacer. For the 2DIR experiments, the sample cell consisted of the sample between a $\mathrm{CaF}_{2}$ convex lens (focal length $1 \mathrm{~m}$ and path length $>500 \mathrm{~nm}$ ) and a $2 \mathrm{~mm}$ regular window. Detailed information on the lens sample cell can be found in ref 44 .

Linear IR Spectroscopy. Fourier transform infrared (FTIR) experiments were performed using a Bruker Tensor 27 spectrometer with $0.5 \mathrm{~cm}^{-1}$ resolution and liquid nitrogencooled narrow band MCT detector. All samples were measured in transmission mode. Each FTIR spectrum was recorded as an average of 40 individual scans at $25{ }^{\circ} \mathrm{C}$.

Two-Dimensional IR Spectroscopy. Two dimensional infrared experiments were performed using a similar setup that was previously described in the literature. ${ }^{52}$ Briefly, Ti:sapphire amplifier (Spectra Physics Mai Tai and Spitfire) with a $5 \mathrm{kHz}$ repletion rate was coupled to an optical parametric amplifier (Spectra Physics, 800C) and a difference frequency generation crystal $\left(\mathrm{AgGaS}_{2}\right)$ to produce $\sim 60 \mathrm{fs}$ broadband infrared pulses. The generated pulses were split into three identical pulses $\left(k_{1}\right.$, $k_{2}$, and $k_{3}$ ) and later focused on the sample with a boxcar configuration. ${ }^{51}$ The time intervals, $\tau$ (time between the first pulse and the second pulse), $T_{\mathrm{w}}$ (time between the second and the third pulse), and $t$ (time between the third pulse and the photon echo), were controlled with four computer-controlled translational stages (PI Micos). The generated photoecho with pulses with parallel polarization $(\langle\mathrm{XXXX}\rangle)$ in the phasematching direction $\left(-\mathbf{k}_{1}+\mathbf{k}_{2}+\mathbf{k}_{3}\right)$ was heterodyned with a fourth pulse (local oscillator) and later dispersed by a Triax monochromator. Finally, the nonlinear signal and local oscillator were detected with a liquid nitrogen-cooled 64 element MCT array detector (Infrared Systems Developments). Here, 2D IR data were collected by scanning $\tau$ time 
from -3 ps to +3 ps in increments of 5 fs for each waiting time in order to collect both the rephasing and nonrephasing data by switching the time ordering. ${ }^{51}$ Signals were collected for waiting times from 0 to $6 \mathrm{ps}$ in steps of $0.5 \mathrm{ps}$ with an additional measurement at $250 \mathrm{fs}$. In all the measurements, the local oscillator always preceded the photon echo signal by $\sim 0.5$ ps. The time domain signal, collected as a function of $\left(\tau, T, \lambda_{\mathrm{t}}\right)$ via a monochromator-array detection, is transformed into the 2DIR spectra $\left(\omega_{\tau}, T, \omega_{t}\right)$ by means of Fourier transforms. A detailed explanation of the Fourier analysis has been described elsewhere. $^{53}$

Ionic Conductivity and Viscosity Measurements. The ionic conductivity of the electrolytes was measured using a YSI 3200 conductivity meter combined with YSI 3250 cell probe. The temperature of the solutions was recorded with the integrated temperature probe of the cell probe. The viscosity of the solutions was measured using a Brookfield DV-II+pro viscometer.

Density Functional Theory Calculations. Density functional theory (DFT) calculations were performed using the Gaussian 09 software, and the $6-311++\mathrm{G}^{* *}$ basis set was used at the B3LYP level of theory. ${ }^{54}$ One lithium-ion with one TFSI-ion and one lithium-ion with two TFSI-ions were geometrically optimized separately for three different solvents, $\mathrm{DMC}, \mathrm{MP}$, and $\mathrm{BC}$, where the number of solvent molecules interacting with the lithium center was selected from 1 to 2 . All DFT computations present in the main text were performed in the gas phase. The vibrational frequencies of each system were calculated, and no imaginary frequencies were observed indicating that the system was in a minimum of energy.

Molecular Dynamics Simulations. Classical molecular dynamics (MD) simulations were performed using SANDER module of the AMBER 16 program package. ${ }^{55}$ Simulations were only performed on the cyclic carbonate-based electrolyte since the other two molecules have conformational isomers which required a more precise description of the system. The $\mathrm{BC}$ and LiTFSI were modeled using the general AMBER force field (GAFF), and a charge scaling factor of 0.8 was used to correct the overestimate of electrostatic point charge. ${ }^{56}$ Moreover, the nonbonding parameters of the lithium-ion were modified according to the values presented in ref 57. Packmol software package was used to build the electrolyte system in a cubic box of $30 \times 30 \times 30 \AA$ with the LiTFSI to $B C$ ratio of 1:2. Periodic boundary conditions were imposed in the simulation. Particle mesh Ewald methodology was used to describe the long range electrostatic interaction with the cutoff of $12 \AA$. The SHAKE algorithm was used to constrain the bonds involving hydrogen. In the simulation, the system was initially energy-minimized for 200 steps using the steepest descent method followed by 300 steps of conjugated gradient method. After the minimization, the system was equilibrated at $500 \mathrm{~K}$ in an isothermal-isobaric ensemble (NPT) for $5 \mathrm{~ns}$ with a time step of 2 fs. The system was cooled down with another NPT run at $300 \mathrm{~K}$ for $3 \mathrm{~ns}$. The Langevin thermostat was used in both NPT runs. The density of the system was used to check that the system has reached equilibrium. Finally, the system was equilibrated in canonical ensemble (NVT) for $1 \mathrm{~ns}$ with a time step of $2 \mathrm{fs}$ before performing the production run at the microcanonical ensemble (NVE). The production run was recorded for $10 \mathrm{~ns}$ in 100 fs steps.

\section{RESULTS}

The characterization of the solvation of LiTFSI at high concentrations in different solvents (i.e., MP, DMC, and BC) was first performed using linear IR spectroscopy. These experiments focused on the carbonyl stretch of the solvent molecules located in the $1700-1820 \mathrm{~cm}^{-1}$ region of the IR spectrum. The IR spectra of LiTFSI in MP (Figure 1) as a

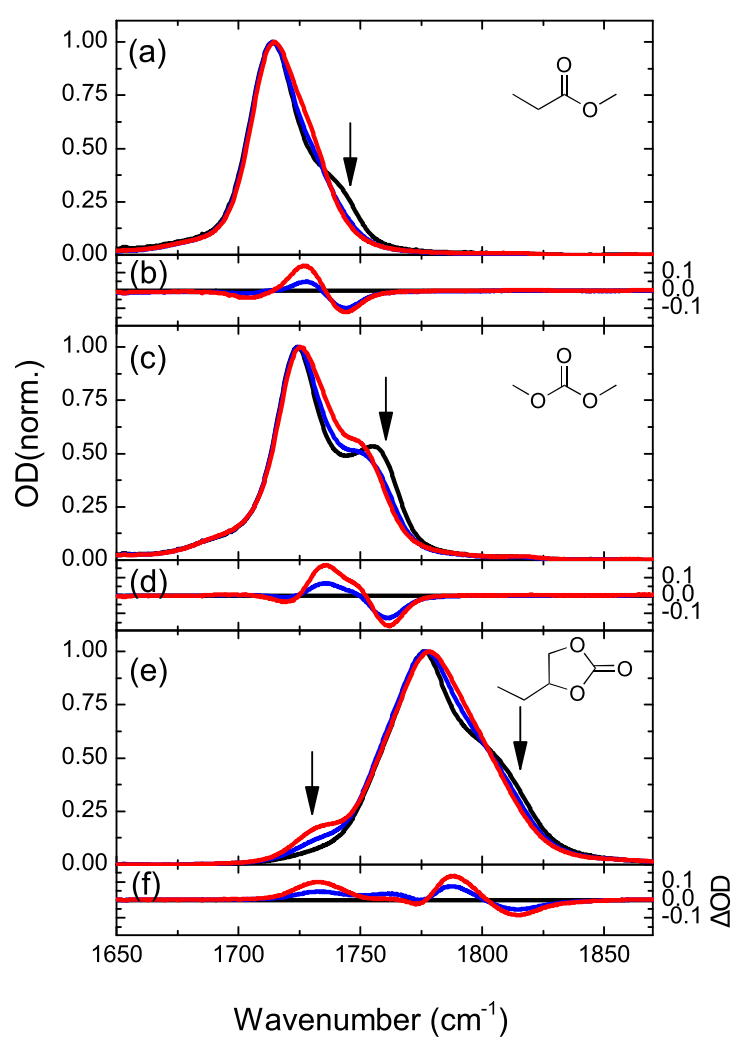

Figure 1. FTIR spectra of LiTFSI in (a) MP, (c) DMC, and (e) BC at $\mathrm{Li}^{+}$:solvent ratio of 1:3 (black), 1:2 (blue), and 1:1.5 (red). (b), (d), and (f) Difference spectra with respect to the 1:3 ratio mixture for MP, DMC, and BC solvent, respectively. Arrows mark the positions of the less visible peaks as discussed in the text.

function of the $\mathrm{Li}^{+}$:solvent ratio show two main bands centered at $\sim 1714$ and $\sim 1741 \mathrm{~cm}^{-1}$, where the band located at higher frequency decreases as the salt concentration increases. The high frequency band is assigned to the free carbonyl stretch mode while the low frequency band is assigned to the coordinated carbonyl stretch mode, which is in agreement with previous assignments. ${ }^{44,45,47,58,59}$ The difference spectra, using the $1: 3$ ratio spectrum as a reference, shows a third band growing between the two main bands as the $\mathrm{Li}^{+}$concentration increases. Simultaneously, two negative peaks appear on either side of the positive peak. While the negative peak at high frequency is caused by a decrease of free carbonyl band, the negative peak at low frequency is likely the product of a frequency shift and bandwidth change in the coordinated peak possibly due to a change in the dielectric constant of the solution $^{60}$ and/or changes in the dynamics of the solution with concentration. $^{44}$ The three proposed bands in the FTIR spectrum are also in agreement with the second derivative of the spectrum (see the Supporting Information). A similar pattern is observed for LiTFSI in the other two solvents (Figure 1) where the coordinated and free bands are located at 

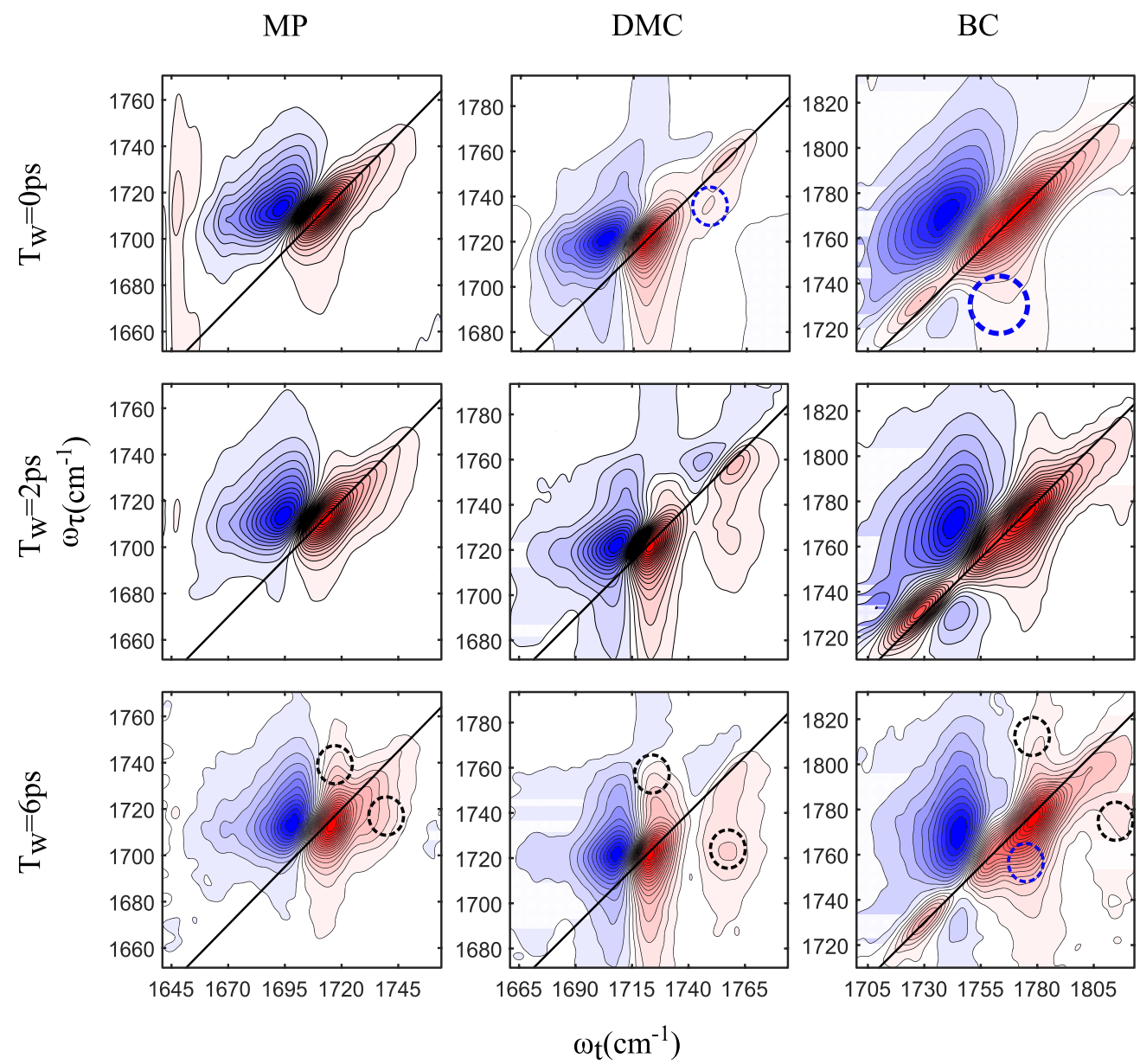

Figure 2. 2DIR spectra of LiTFSI in MP, DMC, and $B C$ of $1: 2 \mathrm{Li}^{+}$:solvent ratio at different waiting times. The positions of the cross peaks are marked in black circles (chemical exchange) and blue circles (vibrational coupling).

$\sim 1724$ and $\sim 1756 \mathrm{~cm}^{-1}$ in DMC and at $\sim 1777$ and $\sim 1814$ $\mathrm{cm}^{-1}$ in BC. These observed changes in the FTIR spectra with salt concentration follow the trends previously seen for the carbonyl stretch of BC and DMC. ${ }^{44}$ However, the intensity of the higher frequency peak and the separation between two observed peaks differ for DMC and BC when compared to MP. Overall, the frequency separation between the peaks follows the trend $\Delta \nu(\mathrm{BC})>\Delta \nu(\mathrm{DMC})>\Delta \nu(\mathrm{MP})$. In addition, the difference spectra of both DMC and $\mathrm{BC}$ solutions show the growth of a band in between the low and high frequency bands in close similarity to that of the MP electrolytes. However, the spectra differ significantly in the width of the carbonyl stretch, which is clearly broader for BC than for the other two solvents. Finally, the spectra of the BC electrolyte show an extra peak, which rises with increasing salt concentration and appears on the lower frequency side of the main band $\left(\sim 1731 \mathrm{~cm}^{-1}\right)$.

The molecular structure and dynamics of the high concentration electrolytes were also investigated by means of 2DIR spectroscopy. Figure 2 shows the 2DIR spectra collected at different waiting times $\left(T_{\mathrm{w}}\right)$ for the 1:2 molar ratio solutions. The 2DIR spectrum for the MP electrolyte at $T_{\mathrm{w}}=0$ ps shows a pair of peaks along the diagonal line where the red contoured peak (positive) [at $\omega \tau, \omega \mathrm{t}=\sim 1713, \sim 1710$ ] arises from the transitions between the ground and first excited vibrational states $(v=0 \leftrightarrow 1)$, while the blue contoured peak (negative) [at $\omega \tau, \omega \mathrm{t}=\sim 1713, \sim 1693$ ] appears due to the transition between first and second excited vibrational states $(v=1 \rightarrow 2)$. The blue peak is downshifted by $\sim 17 \mathrm{~cm}^{-1}$ with respect to the red peak due to the anharmonicity of the carbonyl stretch potential and is in agreement with previous studies. ${ }^{44}$ As in the IR spectra (Figure 1), the coordinated and free carbonyl bands for MP and BC are not resolved in the 2DIR spectra for any of the studied waiting times. In contrast, the DMC spectrum at $T_{\mathrm{w}}=0 \mathrm{ps}$ shows the same two peaks observed in the FTIR spectra (Figure 1).

The $T_{\mathrm{w}}$ evolution of the 2DIR spectra (Figure 2) suggests that the carbonyl stretch modes experience significant changes with time in all samples. Initially, at $T_{\mathrm{w}}=0 \mathrm{ps}$, all samples have peaks elongated along the diagonal line, but as $T_{\mathrm{w}}$ progresses the shape of the peaks becomes more upright manifesting the spectral diffusion process. ${ }^{51}$ However, not all the electrolytes show the same time evolution. For example, the peaks at $T_{\mathrm{w}}=$ 6 ps remain fairly elongated for the $\mathrm{BC}$ electrolyte compared to MP and DMC electrolytes. Furthermore, a substantial difference is observed in $T_{\mathrm{w}}$ dependence of 2DIR spectra due to the growth of off-diagonal features (i.e., cross peaks). In the MP electrolyte, the presence and growth of cross peaks at $\left[\omega_{\tau}, \omega_{\mathrm{t}}=\sim 1713, \sim 1741\right]$ and $\left[\omega_{\tau}, \omega_{\mathrm{t}}=\sim 1741, \sim 1713\right]$ are only evident at longer waiting times, while for the DMC electrolyte, a cross peak appears at $T_{\mathrm{w}}=0$ ps at $\left[\omega_{\tau}, \omega_{\mathrm{t}}=\right.$ $\sim 1736, \sim 1748]$ indicating the presence of vibrationally coupled transitions between the symmetric and asymmetric modes of $\mathrm{Li}(\mathrm{TFSI})_{2}(\mathrm{DMC})_{2}{ }^{44-46,61}$ In addition, the 2DIR 
Scheme 2. (a) Li(TFSI $)_{1}(\text { Solvent })_{2}$, (b) Li(TFSI $)_{2}(\text { Solvent), and (c) Li(TFSI })_{2}(\text { Solvent })_{2}$

(a)

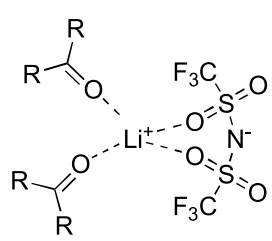

(b)

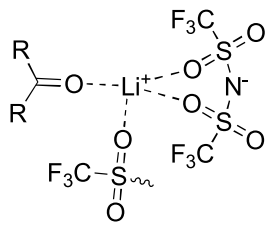

(c)

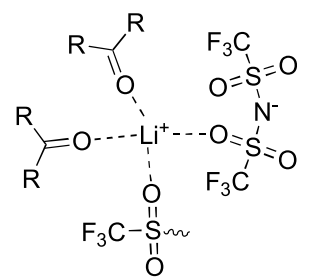

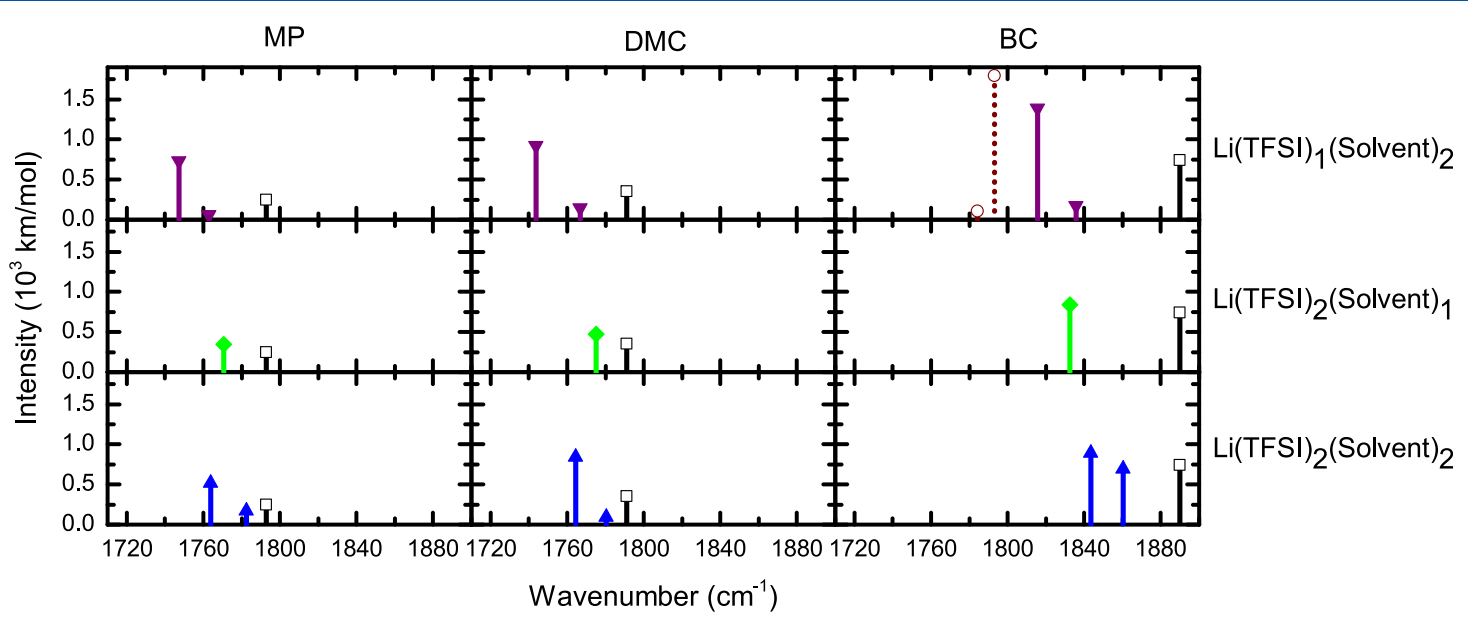

Figure 3. DFT frequency calculations of MP (left), DMC (middle), and BC (right) with different geometries. The top panels represent the frequencies of the coupled transitions of two carbonates which are coordinated to LiTFSI complex. The middle plots correspond to the geometry of a single carbonate coordinated to $\mathrm{Li}(\mathrm{TFSI})_{2}$ complex. The bottom panels show the coupling of two carbonates which are coordinated to $\mathrm{Li}(\mathrm{TFSI})_{2}$ complex. For BC, coupled frequencies of the two carbonates with opposing dipole direction are calculated (brown dashed lines). The frequency of the free solvent molecule is denoted with $\square$ in each plot.

spectra of the DMC electrolyte show the appearance and growth of additional cross peaks at $\left[\omega_{\tau}, \omega_{\mathrm{t}}=\sim 1724, \sim 1756\right]$ and $\left[\omega_{\tau}, \omega_{\mathrm{t}}=\sim 1756, \sim 1724\right]$ with waiting time, which is similar to the 2DIR spectral evolution observed for the MP electrolyte. In the case of the BC electrolytes, the 2DIR spectrum at $T_{\mathrm{w}}=0$ ps shows a cross peak between the lower part of the main band and the isolated lower frequency band, but it does not appear to show changes in intensity with $T_{\mathrm{w}}$. Additionally, the 2DIR spectra of the $\mathrm{BC}$ solution presents three other cross peaks at $\left[\omega_{\tau}, \omega_{\mathrm{t}}=\sim 1777, \sim 1814\right],\left[\omega_{\tau}, \omega_{\mathrm{t}}=\right.$ $\sim 1814, \sim 1777]$, and $\left[\omega_{\tau}, \omega_{\mathrm{t}}=\sim 1757, \sim 1777\right]$, which grow with the waiting time.

\section{DISCUSSION}

It has been previously shown that the preferred coordination number for $\mathrm{Li}^{+}$is four. ${ }^{17,44,49,62-74}$ It is also known that in dilute organic-based electrolytes, $\mathrm{Li}^{+}$exists as free ions, solventseparated ion pairs, contact ion pairs, and aggregates, ${ }^{46,75,76}$ but the number of solvent molecules and $\mathrm{Li}^{+}$ionic speciation directly depends on the availability of solvents in the electrolyte system. In the case of high concertation electrolytes, the ratio of solvent molecules to $\mathrm{Li}^{+}$is lower than four; and it is expected that $\mathrm{Li}^{+}$will not be fully solvated by four solvent molecules. In addition, it has been previously demonstrated that high concentration lithium salt solutions in organic solvents do not tend to form nanoheterogeneous structures. ${ }^{77}$ Therefore, it is expected that this solution will be more homogeneous at the microscopic level, where $\mathrm{Li}^{+}$forms extended aggregates with the anion, and the solvent molecules will interact with $\mathrm{Li}^{+}$to fulfill its coordination number of four. $^{26,63,78}$ This structure is reminiscent of that previously seen in lithium solvates. ${ }^{36-38,41}$ Thus, the formation of lithium centers with one or two solvent molecules in its solvation shell is likely to occur in large proportion in solutions with 1:2 molar ratio, while lithium centers containing more than two solvent molecules should have low occurrences. On the anion, the limited availability of solvent molecules at 1:2 molar ratio forces $\mathrm{TFSI}^{-}$to adopt both bidentate and monodentate coordinations with $\mathrm{Li}^{+}$and to coordinate more than lithium center to fulfill the $\mathrm{Li}^{+}$coordination number of four, as previously seen in the crystal structure of LiTFSI and ethylene carbonate solvates. ${ }^{26}$ Thus, it is reasonable to assume that the FTIR spectra should have the spectral signature corresponding to the different coordinating species (Scheme 2): Li$(\text { TFSI })_{1}(\text { Solvent })_{2}, \operatorname{Li}(\text { TFSI })_{2}($ Solvent $)$, and Li$(\text { TFSI })_{2}$ (Solvent $)_{2}$.

The FTIR spectra as a function of concentration (Figure 1) show the rise and disappearance of different bands. In particular, all the solvents show more than one band at the ratio of $\left[\mathrm{Li}^{+}\right.$:solvent $]=1: 1.5$. However, the presence of multiple bands could arise from the strong vibrational coupling between carbonyl stretches of two solvent molecules coordinating the same lithium center, such as in the case of $\mathrm{Li}(\mathrm{TFSI})_{1}$ (Solvent $)_{2}$ and $\mathrm{Li}(\mathrm{TFSI})_{2}$ (Solvent $)_{2}$, which split the transition in two. ${ }^{58}$ This splitting is a consequence of having two strongly coupled and degenerated transitions. The vibrational Hamiltonian of vibrationally coupled carbonyl stretches is represented by 

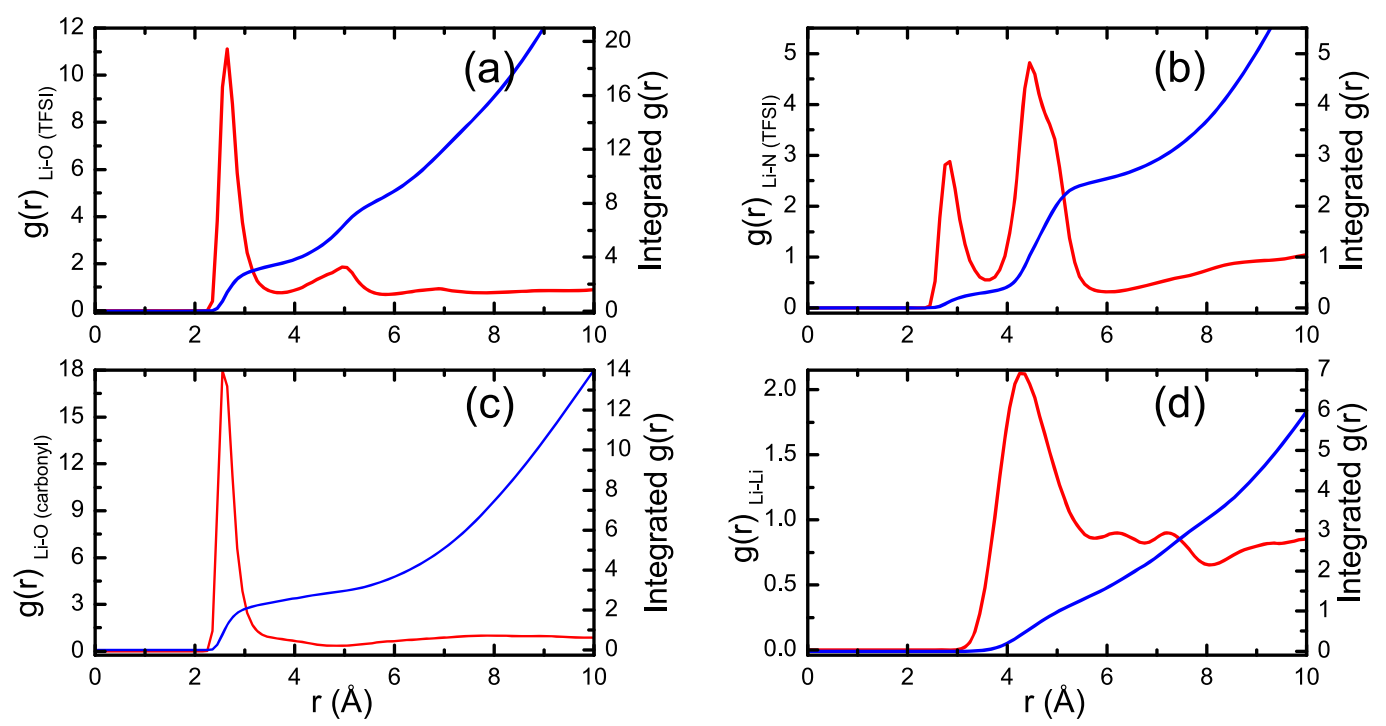

Figure 4. Radial distribution function, $g(r)$, and the integrated $g(r)$ obtained from $\mathrm{MD}$ simulations for $(\mathrm{a}) \mathrm{Li}-\mathrm{O}_{\mathrm{TFSI}},(\mathrm{b}) \mathrm{Li}-\mathrm{N}_{\mathrm{TFSI}},(\mathrm{c}) \mathrm{Li}-\mathrm{O}_{\text {carbonyl }}$ and (d) $\mathrm{Li}-\mathrm{Li}$.

$$
\hat{H}=\left[\begin{array}{cc}
\omega_{10}+\delta \omega^{a}(t) & \beta(t) \\
\beta(t) & \omega_{10}+\delta \omega^{b}(t)
\end{array}\right]
$$

containing two solvent molecules (i.e., structures of the form $\left.\mathrm{Li}(\mathrm{TFSI})_{x}(\text { Solvent })_{2}\right)$ appears to be governed by the chemical structure of the solvent. It is important to note that similar trends in vibrational frequency positions and intensities are observed when a polarizable dielectric medium is used (see the Supporting Information).

The computed DFT frequency separations and transition dipole magnitudes for the carbonyl stretch transitions in the different $\mathrm{Li}^{+}$-solvent complexes appear to explain the overall carbonyl stretch line shape and its concentration dependence. First, the frequency separations between $\mathrm{Li}(\mathrm{TFSI})_{2}$ (Solvent $)_{2}$ and $\operatorname{Li}(\mathrm{TFSI})_{1}$ (Solvent) $)_{2}$ justify the bandwidth of the carbonyl stretch bands because of the similarity between the frequency separation and the experimental line width trends (i.e., $\Delta \nu(\mathrm{BC})>\Delta \nu(\mathrm{DMC}) \approx \Delta \nu(\mathrm{MP}))$. Second, the computations predict that the carbonyl band of $\operatorname{Li}(\mathrm{TFSI})_{2}$ (Solvent) ${ }_{1}$ should be located in between the free and the $\operatorname{Li}(\text { TFSI })_{1}$ (Solvent $)_{2}$ species. The peak corresponding to the $\mathrm{Li}(\mathrm{TFSI})_{2}$ (Solvent) ${ }_{1}$ is definitely seen in all samples as a growing peak when the $\mathrm{Li}^{+}$:solvent ratio is increased from $1: 3$ to $1: 1.5$. Third, the position of the $\mathrm{Li}(\mathrm{TFSI})_{1}$ (Solvent) $)_{2}$ carbonyl band is predicted to have the lowest frequency position of the three species. The position of this species explains why the maxima location of the carbonyl band remains unaltered for the investigated $\mathrm{Li}^{+}$:solvent ratio since $\mathrm{Li}(\mathrm{TFSI})_{1}$ (Solvent $)_{2}$ is the most likely species to be formed at $1: 3$ to $1: 1.5$ ratios. Finally, the peak at the highest frequency, which decreases when the $\mathrm{Li}^{+}$ concentration is increased, corresponds to "free" solvent molecules. While it sounds counterintuitive to propose the presence of free solvent molecules in such high concentrated solution, the molecular interactions in these solutions are strongly dictated by the ion-ion ${ }^{43}$ and weakly constrained by ion-solvent interactions. ${ }^{43}$ In this particular case, the existence of free solvent molecules evidence the presence of intermediate states in which a solvent molecule diffuses in and out from a lithium center, as it hops between different $\mathrm{Li}^{+}$centers. This band assignment is in agreement with the observation of a fast coordination/decoordination of solvent molecules in these high concentration electrolytes (see below).

The $\mathrm{Li}^{+}$solvation shell deduced from the FTIR and DFT computations is also in agreement with the MD simulation. 
The integrated $g(r)$ for the $\mathrm{Li}^{+}-\mathrm{O}$ (TFSI) is $\sim 3.4$ at $3.55 \AA$ (Figure 4 ), indicating that on average more than one $\mathrm{TFSI}^{-}$ coordinates with a lithium center. In other words, $\mathrm{TFSI}^{-}$has both bidentate and monodentate coordination with $\mathrm{Li}^{+}$. The bidentate coordination of $\mathrm{TFSI}^{-}$to $\mathrm{Li}^{+}$results in a $\mathrm{TFSI}^{-}$ conformation where its nitrogen atom points away from the lithium center. As a result, the nitrogen atom is positioned closer to a different lithium center (Figure 4). The $g(r)$ of $\mathrm{Li}-$ $\mathrm{N}$ (TFSI) confirms the bidentate arrangement through the presence of two peaks at 4.45 and $2.85 \AA$, where the latter accounts for the low probability of finding the nitrogen atom pointing away from one lithium center (Figure 4). The complete coordination structure of $\mathrm{Li}^{+}$is derived from the $g(r)$ of $\mathrm{Li}-\mathrm{O}$ (carbonyl) (Figure 4). The integrated $g(r)$ shows that on average $2.5 \mathrm{BC}$ molecules coordinate each $\mathrm{Li}^{+}$. Note that the coordination number of $\mathrm{BC}$ exceeds the $\mathrm{Li}^{+}$:solvent molar ratio of the system due to the sharing of $\mathrm{BC}$ molecules between different lithium centers (Figure 4). Thus, the $\mathrm{Li}^{+}$solvation shell arrangement derived from the MD simulations agrees with the presence of the previously proposed species; i.e., $\mathrm{Li}(\text { TFSI })_{1}$ (Solvent $)_{2}, \quad \operatorname{Li}(\text { TFSI })_{2}($ Solvent $)$, and Li$(\text { TFSI })_{2}$ (Solvent $)_{2}$.

Another important feature observed in the FTIR spectra (Figure 1) as well as 2DIR spectra (Figure 2) is the low frequency band in the $\mathrm{BC}$ sample. This band rises when the $\mathrm{Li}^{+}$ concentration is increased. This lowest frequency band in the $\mathrm{BC}$ carbonyl spectrum was previously observed in $\mathrm{Li}^{+}$solutions of $\mathrm{BC}$ and was attributed to the formation of ion pairs and aggregates. ${ }^{44}$ However, the solution of $\mathrm{Li}^{+}$with $\mathrm{TFSI}^{-}$as the counterion at 1:2 molar ratio of $\mathrm{Li}^{+}$:solvent also shows this band (Figure 1). Therefore, the peak appearing at the lower frequency side of the carbonyl band is not likely to arise from the carbonyl groups interacting with a single $\mathrm{Li}^{+}$, but from carbonyl groups of two different and adjacent $\mathrm{Li}^{+}$centers forming a dimer (Scheme 3). The dimer formation by BC

\section{Scheme 3. Proposed Structure of the BC Dimer ${ }^{a}$}

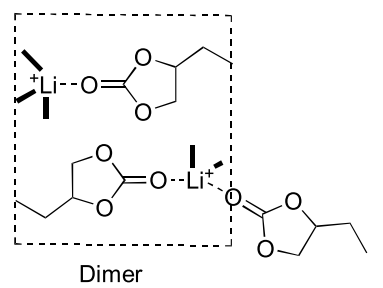

${ }^{a}$ Broad black lines represent the coordination of $\mathrm{Li}^{+}$with either solvent molecules or anions.

carbonate molecules in the solvation shell of $\mathrm{Li}^{+}$is not new since it has been previously observed in a LiTFSI:EC solvate ${ }^{26}$ and predicted theoretically in another cyclic carbonate, propylene carbonate. $^{79}$ In the solvate structure, two EC molecules coordinating two different lithium centers are observed to be an arrangement where both EC molecules are almost parallel to each other but with their dipoles are pointing in opposite directions. ${ }^{26}$ This type of structure was predicted to have a stabilization energy of $\sim 20 \mathrm{~kJ} / \mathrm{mol}^{79}$ The DFT-calculated frequencies of the dimeric BC structure (dashed lines Figure 3) are in agreement with the assignment of the low frequency band in the FTIR spectra. Therefore, it is proposed that the dimeric $\mathrm{BC}$ structures between two different $\mathrm{Li}^{+}$are the cause of the low frequency band in high concentration BC electrolytes. In addition, the high transition dipole predicted for the dimer transition and the small area of the dimmer band observed experimentally demonstrate the small occurrence of such a structure in the BC electrolyte. The assignment of this low frequency band to a dimer is also consistent with the 2DIR spectra where a cross peak between this band and the main carbonyl band of $\mathrm{BC}$ at $T_{\mathrm{w}}=0 \mathrm{ps}$ (Figure 2 at $\left[\omega_{\tau}, \omega_{\mathrm{t}}=\sim 1732, \sim 1767\right]$ ) is observed. This cross peak arises from the vibrational coupling between the high intensity dimer transition and the other two carbonyl groups solvating $\mathrm{Li}^{+}$which do not form the dimer (Scheme 3).

The presence of the $\mathrm{BC}$ dimer between different $\mathrm{Li}^{+}$should impose a microscopic ordering to the solution that should manifest macroscopically. Indeed, the viscosity of the $\mathrm{BC}$ solutions exhibits the microscopic ordering at the macroscopic level since the electrolyte shows a viscosity more than six times larger than that of the MP and DMC electrolytes (Table 1).

Table 1. Measured Conductivity and Viscosity of LiTFSI in Different Solvents at 1:2 Salt:Solvent Ratio ${ }^{a}$

$\begin{array}{cccc} & \begin{array}{c}\text { conductivity }(\mathrm{mS} . \\ \left.\mathrm{cm}^{-1}\right)\end{array} & \begin{array}{c}\text { viscosity } \\ (\mathrm{cP})\end{array} & \begin{array}{c}\text { viscosity-conductivity } \\ \text { product }\end{array} \\ \text { MP } & 2.3 & 21.6 & 49.7 \\ \text { DMC } & 1.2 & 53.7 & 64.9 \\ \text { BC } & 0.2 & 323 & 64.6\end{array}$

${ }^{a}$ All the solutions are measured at $25{ }^{\circ} \mathrm{C}$.

The difference between the viscosities of the electrolytes is due to the lack of dimerization in DMC or MP caused by the absence of strictly planar structures in these two linear molecules. ${ }^{80,81}$ While one can propose that the difference in the viscosity is due to the interaction potential between the solvent molecule and $\mathrm{Li}^{+}$, DFT computations predict similar $\mathrm{Li}^{+}$---solvent energetics for all the solvents (Figure 5). Furthermore, a nonlinear change in viscosity is observed for electrolytes made of a mixture of BC and DMC, while the viscosity changes linearly for electrolytes made of DMC and MP (see the Supporting Information). The nonlinear behavior of the viscosity in the $\mathrm{BC}-\mathrm{DMC}$ electrolyte evidences the nonideal behavior of the $\mathrm{BC}-\mathrm{DMC}$ solution due to the existence of the $\mathrm{BC}-\mathrm{BC}$ dimer interaction, which is not present in the DMC-MP electrolyte. In terms of nonideal solutions, the nonlinear viscosity is a result of the excess free energy caused by the difference in the interaction potential between $\mathrm{BC}-\mathrm{BC}, \mathrm{DMC}-\mathrm{DMC}$, and $\mathrm{DMC}-\mathrm{BC}$.

The results showed so far reveal that ionic and molecular species coordinate simultaneously the different lithium centers in high concentration electrolytes. In addition, the ordering in the molecular structure appears to extend beyond a single $\mathrm{Li}^{+}$ due to the bridging of $\mathrm{TFSI}^{-}$and dimer formation only in the case of BC. The dynamics of the molecular components around the lithium center are investigated via 2DIR spectroscopy. In particular, the motions of the solvent molecules are derived from temporal dependence of decorrelation between pump and probe frequencies of the carbonyl stretch in the 2DIR spectra, which is computed by measuring the nodal slope. ${ }^{82}$ This decorrelation metric is usually assigned to the motions of the environment. ${ }^{51}$ However, the carbonyl frequencies in coordinated band do not provide direct information on the molecular motions bound to $\mathrm{Li}^{+}$because the strong coupling gives rise to mixed states (eq 2). ${ }^{44}$ Thus, the decorrelation of the mixed state frequencies does not have 

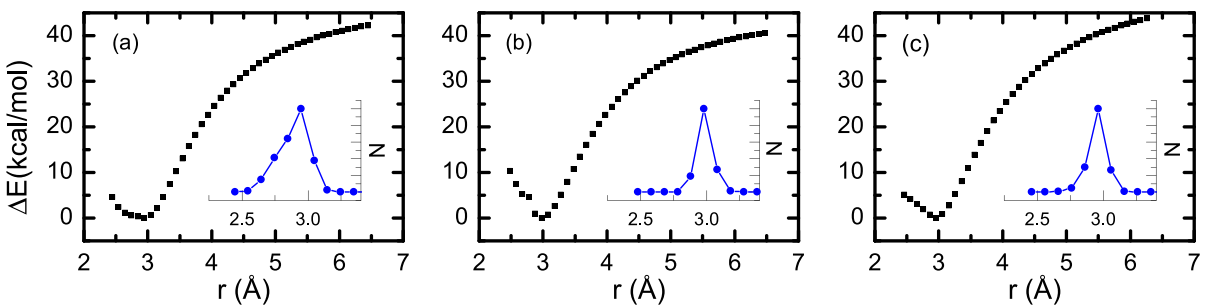

Figure 5. Potential energy scan as a function of the distance between the lithium cation and carbonyl carbon of each solvent: (a) MP, (b) DMC, and (c) BC. The insets represent the Boltzmann distribution in each system.
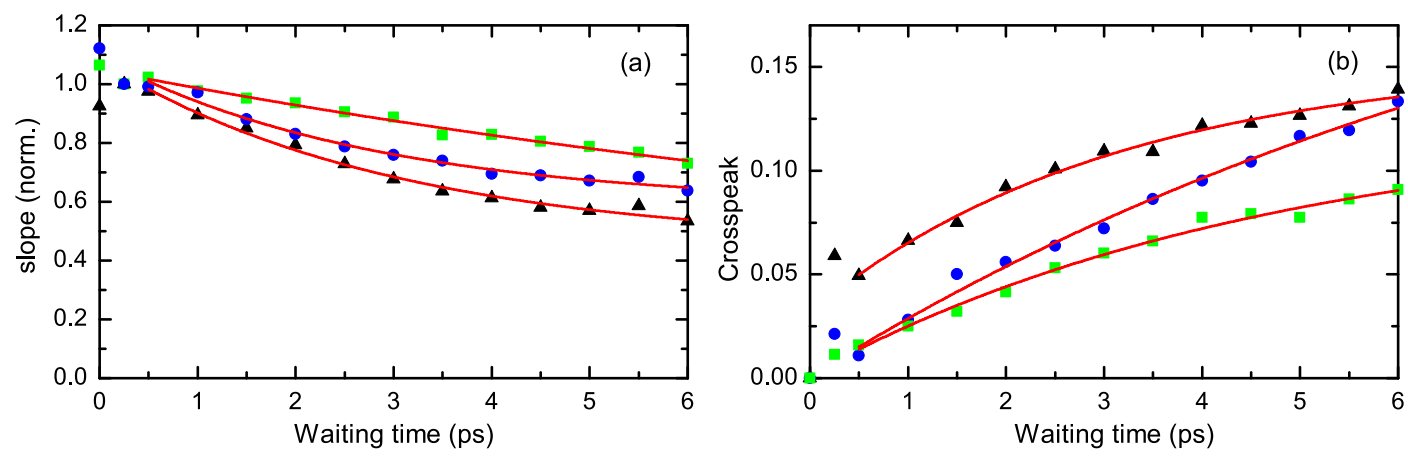

Figure 6. Inverse slope (normalized at $250 \mathrm{fs}$ ) of the coordinated carbonyl stretch (a) and the cross peak growth (b) of electrolytes made of MP (blue), DMC (black), and BC (green) at 1:2 molar ratio. The exponential fittings are represented with red lines.

Table 2. Calculated Characteristic Time of the Slope and the Cross Peak Growth

\begin{tabular}{|c|c|c|c|c|c|c|}
\hline & \multicolumn{3}{|c|}{ slope $^{a}$} & \multicolumn{3}{|c|}{ cross peak growth } \\
\hline & $A$ & $\tau(\mathrm{ps})$ & $y_{0}$ & $B$ & $\tau_{\mathrm{c}}(\mathrm{ps})$ & $z_{0}$ \\
\hline MP & $0.50 \pm 0.02$ & $2.8 \pm 0.5$ & $0.59 \pm 0.03$ & $0.26 \pm 0.07$ & $9 \pm 3$ & $0.27 \pm 0.07$ \\
\hline DMC & $0.62 \pm 0.03$ & $3.0 \pm 0.4$ & $0.45 \pm 0.03$ & $0.12 \pm 0.01$ & $3 \pm 1$ & $0.15 \pm 0.01$ \\
\hline $\mathrm{BC}$ & $1.04 \pm 0.01$ & $17.3 \pm 0.7$ & - & $0.12 \pm 0.01$ & $5 \pm 1$ & $0.13 \pm 0.02$ \\
\hline
\end{tabular}

${ }^{a}$ Dynamics was validated using integrated photon echo shift (see the Supporting Information).

a direct correspondence with individual carbonyl frequency fluctuations, and the FFCF dynamics represent a change in the geometrical structure of the carbonyl groups, i.e., the relative angle or the distance between carbonyl groups. ${ }^{44}$

The temporal evolution of the slope for the carbonyl band of the three solutions are shown in Figure 6. The slope dynamics show a decay with waiting time for all the samples and are well modeled with a single exponential decay of the form $f(t)=y_{0}+$ $A \mathrm{e}^{-t / \tau}$, where $\tau$ is the characteristic time of exponential decay. In this model, the exponential decay and the offset $\left(y_{0}\right)$ represent two dynamical processes with fast and slow dynamics, respectively. The modeling parameters (Table 2) evidence that MP and DMC have fast decorrelation dynamics with a similar time scale of $\sim 3$ ps, but the amplitude of the slow dynamic component is larger for MP. In contrast, the dynamics for the fast component of the $\mathrm{BC}$ electrolyte present an almost linear decay to zero exposing the very slow motions shown by the $\mathrm{BC}$ molecules. In all samples, the second component (offset) of the FFCF dynamics is assigned to the interchange between possible arrangements of different $\mathrm{Li}^{+}$ solvation shells. The assignment of slow motions to different solvation shell structures explains the large offset seen for MP and DMC (Table 2) since both molecules have a large number of conformers from their mobile alkyl chains. In addition, the conformational changes in MP and DMC perturb their molecular dipole directions ${ }^{83}$ creating a large number of different solvent coordination angles or, equivalently, tran- sitions. In contrast, the rigid structure of the cyclic carbonate and the formation of dimers significantly restrict the changes in the dipole direction and structure deformation, respectively. As a result, $\mathrm{BC}$ electrolytes present an overall slow dynamics with a negligible slow component.

The 2DIR spectra also reveal the presence of cross peaks (Figure 2). While intraband cross peaks originate from vibrational coupling between two or more vibrational modes, ${ }^{84}$ the cross peaks between vibrational transitions corresponding to different chemical species are caused by chemical exchange. ${ }^{85}$ In particular, the cross peak between the main carbonyl band and the high frequency band is proposed to arise from solvent molecules coordinating and decoordinating from the lithium center. Note that this mechanism is not similar to that proposed by Cho and co-workers ${ }^{75}$ because these concentrated solutions are dominated by ion-ion interactions rather than by ion-dipole interactions, as demonstrated by the Watanabe group. ${ }^{43}$ The dominating ion-ion interactions in the high concentration electrolyte allow us to postulate that the molecular mechanism behind the coordination and decoordination of solvent molecules from $\mathrm{Li}^{+}$ is a consequence of the change in the $\mathrm{Li}^{+}-\mathrm{TFSI}^{-}$interaction. In particular, the variation in the ion-ion interaction is likely to arise from conformational changes of a nearby $\mathrm{TFSI}^{-}$since it has been previously shown that the energetics of the conformational change of $\mathrm{TFSI}^{-}$are low and thermally allowed. ${ }^{86-88}$ In other words, the conformational changes of 
Scheme 4. Molecular Mechanism Giving Rise to the Change in the Coordination of $\mathrm{Li}^{+}$

$$
\begin{gathered}
\mathrm{Li}(\mathrm{TFSI})(\text { Solvent })_{2}+\mathrm{TFSI} \leftrightarrow \mathrm{Li}(\mathrm{TFSI})_{2}(\text { Solvent })_{2} \\
\mathrm{Li}(\mathrm{TFSI})_{2}(\text { Solvent })_{2} \leftrightarrow \mathrm{Li}(\mathrm{TFSI})_{2}(\text { Solvent })+\text { Solvent }
\end{gathered}
$$
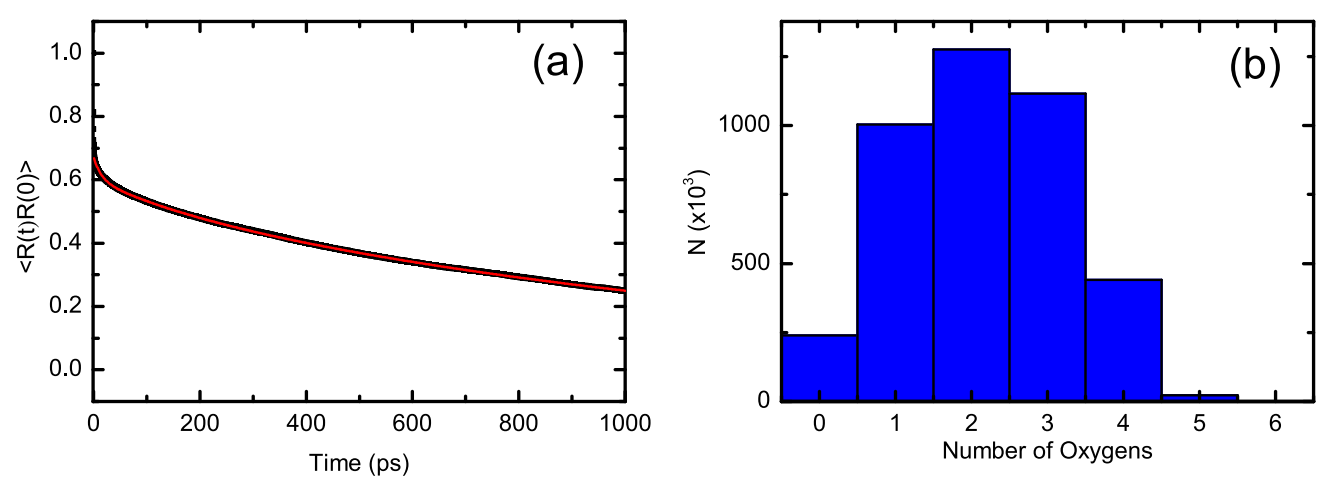

Figure 7. (a) Autocorrelation function (black squares) and modeling (red line) of the residence time of $\mathrm{O}-\mathrm{BC}$ at the cutoff value of $3.15 \AA$ from the lithium center and (b) the histogram of number of oxygen residing within the cutoff value.

a TFSI $^{-}$are likely to vary the total coordination number of a neighboring lithium center, and as a result, a solvent molecule is expelled from the $\mathrm{Li}^{+}$solvation shell to reestablish the coordination number of four. However, the expelled or "free" solvent molecule will "rapidly" establish a new interaction with the same or another $\mathrm{Li}^{+}$due to the close proximity among lithium centers in the high concentration electrolyte (Figure 4). Hence, the existence of cross peaks between coordinated and free carbonyl bands evidences the formation and disappearance of transient states where the solvent molecule is temporally located in between lithium centers.

The proposed mechanism for the cross peaks observed in the 2DIR spectra is validated with the MD simulation. In this mechanism, the hypothesis in which coordination of TFSI ${ }^{-}$ affects the number of solvent molecules interacting with the lithium center is first tested. To this end, the correlation between the number of oxygen atoms from $\mathrm{BC}$ carbonyl and $\mathrm{TFSI}^{-}$sulfone groups is derived from the MD simulations. The results show that the numbers of $\mathrm{BC}$ oxygen atoms and $\mathrm{TFSI}^{-}$ ion are inversely correlated (see the Supporting Information) with a correlation number of 0.73 indicating a strong correlation. ${ }^{89}$ The observed correlation between the number of species coordinating $\mathrm{Li}^{+}$demonstrates that the decoordination of one $\mathrm{BC}$ molecule from the lithium center is in fact related to the changes in the coordination of $\mathrm{TFSI}^{-}$. Thus, a mechanism is proposed consisting of a $\mathrm{TFSI}^{-}$coordinating $\mathrm{Li}^{+}$ rearranging to coordinate a different $\mathrm{Li}^{+}$and triggering the expulsion of the solvent molecule (Scheme 4).

In accordance with the proposed coordination and decoordination model, the intensity of the cross peaks grows as a function of waiting time (Figure 6). Modeling of the cross peak growth with an exponential function reveals that the dynamics of the carbonyl coordination and decoordination process are similar for the three solvent molecules (Table 2). However, it is apparent that MP has a larger time constant than the other two carbonates. To understand the difference in the dynamics, the potential energy between $\mathrm{Li}^{+}$and a solvent molecule was calculated via DFT computations. Note that these calculations only consider a solvent molecule and $\mathrm{a} \mathrm{Li}^{+}$ because according to the mechanism the solvent exchange occurs from the same intermediate state (i.e., Li$\left.(\mathrm{TFSI})_{2}(\text { Solvent })_{2}\right)$, which is the same for all the samples.
The potential energy surfaces of the $\mathrm{C}=\mathrm{O} \cdots \mathrm{Li}^{+}$coordinate for all the solvents show a similar potential barrier (Figure 5) indicating that the energetics are not responsible for the difference in the dynamics. However, the $\mathrm{C}=\mathrm{O} \cdots \mathrm{Li}^{+}$potential surface reveals that the minimum of the well is less concave for MP than for the other two solvents (Figure 5). In terms of Kramer's theory, the result demonstrates that MP will have a higher probability of remaining in the well or, equivalently, slow dynamics. ${ }^{90}$ These theoretical calculations also establish that the trend of the chemical exchange dynamics is defined exclusively by the interaction potential between $\mathrm{Li}^{+}$and the carbonyl group of the solvent molecule.

The dynamics of the solvent coordination and decoordination process were also derived from the MD simulation. The $\mathrm{MD}$ simulations reveal that there is a large variety of solvation shell structures as seen in the histogram of BC carbonyl oxygen atoms in the solvation shell of $\mathrm{Li}^{+}$(Figure 7). Hence, the chemical exchange rate is obtained from the residence time, which is defined as the time that a solvent molecule resides close to a lithium center. ${ }^{91}$ In this case, a solvent molecule is considered to be residing with a $\mathrm{Li}^{+}$if the oxygen of the carbonyl group is within $3.15 \AA$ of $\mathrm{Li}^{+}$. The autocorrelation function of the residence time $(R(t))$ of all the BC molecules in the trajectory was calculated as $\langle R(t) R(0)\rangle$. The correlation function (Figure 7 ) shows a temporal dependence that is well modeled with three exponential decays of the form $f(t)=$ $A_{1} \mathrm{e}^{-t / \tau 1}+A_{2} \mathrm{e}^{-t / \tau 2}+A_{3} \mathrm{e}^{-t / \tau 3}$, where $A_{i}$ and $\tau_{i}$ correspond to the amplitude and the characteristic time of the ith dynamical component, respectively. The characteristic times of the autocorrelation, as estimates of the time scale for the chemical exchange process, reveal components with time constants of $\sim 10 \mathrm{ps}, \sim 200 \mathrm{ps}$, and $\sim 1 \mathrm{~ns}$ (see the Supporting Information). While the fast correlation decay confirms that the coordination and decoordination of solvent molecules from the lithium center form a thermally allowed process with a picosecond time constant, the slow decays of the autocorrelation are likely to arise from the low probability of exchanging both solvent molecules simultaneously in agreement with the proposed mechanism (Scheme 4). This result further supports our hypothesis for the chemical exchange being the mechanism for the observed cross peaks between the coordinated and free peak of the carbonyl bands. In addition, the derived time 
constant for the chemical exchange dynamics is in reasonable agreement with the experimental one.

The coordination and decoordination of the solvent molecule are consequences of the change in the coordination of $\mathrm{TFSI}^{-}$with the lithium center. This mechanism is expected to be the same molecular mechanism that will enable charge transport through the high concentration electrolyte and was previously postulated by the Watanabe group. ${ }^{78,92,93}$ In particular, it has been proposed that the exchange of the solvent/anion from the lithium centers in a solvent/anionbridged-structured electrolyte results in a hopping-based (nonvehicular) conduction mechanism in lithium bis(fluorosulfonyl)amide (LiTFS)-based electrolytes. ${ }^{78,93}$ Hence, we propose that the same type of ionic conduction mechanism exists for the high concentration electrolytes studied here. This proposed conduction mechanism is supported by the high conductivity exhibited by all the electrolytes (Table 1) since a high conductivity is not expected via a vehicular type conduction mechanism in electrolytes dominated by ion-ion interactions. ${ }^{94}$ In the case of the three investigated electrolytes, the conductivity of the cyclic carbonate-based electrolyte appears to be lower than that of its linear analogues. However, the viscosity-weighted conductivities (Table 1) show similar values, indicating all electrolytes should have the same number of charge carriers. ${ }^{94}$ Furthermore, it is observed that the MP electrolyte has the lower viscosity-weighted conductivity and the slower chemical exchange dynamics, while DMC and BC have the faster exchange dynamics and the higher viscosityweighted conductivities. The observed correlation between conductivity and chemical exchange rate arises from the close relationship between the number of $\mathrm{TFSI}^{-}$and solvent molecules coordinating the same $\mathrm{Li}^{+}$, as previously demonstrated. In other words, the coordination and decoordination of solvent molecules directly track the change in the TFSI ${ }^{-}$ coordination type and number to a lithium center. Thus, the exchange of solvent molecules from $\mathrm{Li}^{+}$solvation shell directly follows the making and breaking of ionic structures in the high concentration electrolyte, or equivalent, and its conductivity; giving that the change of the TFSI ${ }^{-}$coordination to $\mathrm{Li}^{+}$is the molecular process most related to the conductivity.

\section{CONCLUSION}

The structural interactions and the motions of three different high concentration electrolytes were investigated. The linear vibrational spectra and DFT calculations suggested that the anions and solvent molecules present a similar coordination with the lithium center in the three electrolytes. The experiments also reveal the presence of multiple anions coordinating with the lithium centers, which creates shortrange-ordered clusters in all the electrolytes. The presence of additional interaction in cyclic carbonate-based electrolyte is also demonstrated. This interaction results in the formation of BC dimers from molecules coordinated to different $\mathrm{Li}^{+}$, and gives rise to an additional structural ordering in the $\mathrm{BC}$ electrolyte, which is directly seen in its viscosity. Our experiments also reveal that the process of coordination and decoordination of solvent molecules from lithium centers is directly related to the coordination between the anion and the cation. However, the characteristic time of the chemical exchange process is found to be governed by the chemical nature of the solvent molecules. Overall, our experiments reveal the connection between the molecular characteristic of the electrolyte components and indicate that small changes in the solvent-solvent interaction potential have drastic effects on the macroscopic properties of the electrolytes, such as its viscosity.

\section{ASSOCIATED CONTENT}

\section{Supporting Information}

The Supporting Information is available free of charge at https://pubs.acs.org/doi/10.1021/acs.jpcb.9b10795.

Second derivative of all FTIR spectra (Figure S1), additional 2DIR spectra (Figure S2), DFT frequency calculations in different polarizable mediums (Figure S3), carbonyl stretch frequency as a function of $\mathrm{Li}-\mathrm{O}$ distance (Figure S4); number of coordinated oxygen of $\mathrm{BC}$ vs TFSI ion (Figure S5); viscosity of the 1:2 $\mathrm{Li}^{+}$:solvent in $\mathrm{BC} / \mathrm{DMC}$ mixture and MP/DMC mixture (Figure S6); DFT frequencies and intensities of different geometries in different solvents (Table S1); characteristic times obtained from photon echo peak shift method (Table S2); characteristic times obtained from autocorrelation of residence time (Table S3); force field validation and cutoff distance explanation (PDF)

\section{AUTHOR INFORMATION}

\section{Corresponding Author}

Daniel G. Kuroda - Department of Chemistry, Louisiana State University, Baton Rouge, Louisiana 70803, United States; 다이.org/0000-0002-4752-7024; Phone: (+1) 225-5781780; Email: dkuroda@lsu.edu

\section{Author}

Susith R. Galle Kankanamge - Department of Chemistry, Louisiana State University, Baton Rouge, Louisiana 70803, United States

Complete contact information is available at: https://pubs.acs.org/10.1021/acs.jpcb.9b10795

\section{Notes}

The authors declare no competing financial interest.

\section{ACKNOWLEDGMENTS}

The authors acknowledge financial support from the National Science Foundation (CHE- 1751735) and the LSU Chemistry Department. The authors also acknowledge the High Performance Computing Center at Louisiana State University and the Louisiana Optical Network Initiative (LONI) for computer time.

\section{REFERENCES}

(1) Amine, K.; Kanno, R.; Tzeng, Y. H. Rechargeable lithium batteries and beyond: Progress, challenges, and future directions. MRS Bull. 2014, 39 (5), 395-405.

(2) Etacheri, V.; Marom, R.; Elazari, R.; Salitra, G.; Aurbach, D. Challenges in the development of advanced li-ion batteries: A review. Energy Environ. Sci. 2011, 4 (9), 3243-3262.

(3) Goodenough, J. B.; Kim, Y. Challenges for rechargeable li batteries. Chem. Mater. 2010, 22 (3), 587-603.

(4) $\mathrm{Xu}, \mathrm{K}$. Electrolytes and interphases in li-ion batteries and beyond. Chem. Rev. 2014, 114 (23), 11503-11618.

(5) Johnson, L.; Li, C. M.; Liu, Z.; Chen, Y. H.; Freunberger, S. A.; Ashok, P. C.; Praveen, B. B.; Dholakia, K.; Tarascon, J. M.; Bruce, P. $\mathrm{G}$. The role of lio2 solubility in $\mathrm{o}-2$ reduction in aprotic solvents and its consequences for li-o-2 batteries. Nat. Chem. 2014, 6 (12), 10911099. 
(6) Gauthier, M.; Carney, T. J.; Grimaud, A.; Giordano, L.; Pour, N.; Chang, H. H.; Fenning, D. P.; Lux, S. F.; Paschos, O.; Bauer, C.; et al. Electrode-electrolyte interface in li-ion batteries: Current understanding and new insights. J. Phys. Chem. Lett. 2015, 6 (22), 46534672.

(7) Nitta, N.; Wu, F. X.; Lee, J. T.; Yushin, G. Li-ion battery materials: Present and future. Mater. Today 2015, 18 (5), 252-264.

(8) Wang, J. H.; Yamada, Y.; Sodeyama, K.; Chiang, C. H.; Tateyama, Y.; Yamada, A. Superconcentrated electrolytes for a highvoltage lithium-ion battery. Nat. Commun. 2016, 7, DOI: 10.1038/ ncomms 12032 .

(9) Yamada, Y.; Yaegashi, M.; Abe, T.; Yamada, A. A superconcentrated ether electrolyte for fast-charging li-ion batteries. Chem. Commun. 2013, 49 (95), 11194-11196.

(10) Suo, L. M.; Hu, Y. S.; Li, H.; Armand, M.; Chen, L. Q. A new class of solvent-in-salt electrolyte for high-energy rechargeable metallic lithium batteries. Nat. Commun. 2013, 4, DOI: 10.1038/ ncomms2513.

(11) Liang, H. Y.; Li, H.; Wang, Z. X.; Wu, F.; Chen, L. Q.; Huang, $\mathrm{X}$. J. New binary room-temperature molten salt electrolyte based on urea and litfsi. J. Phys. Chem. B 2001, 105 (41), 9966-9969.

(12) Chen, R. J.; Wu, F.; Li, L.; Qiu, X.; Chen, L. Q.; Chen, S. The structure-activity relationship studies of binary room temperature complex electrolytes based on litfsi and organic compounds with acylamino group. Vib. Spectrosc. 2007, 44 (2), 297-307.

(13) Jeong, S. K.; Seo, H. Y.; Kim, D. H.; Han, H. K.; Kim, J. G.; Lee, Y. B.; Iriyama, Y.; Abe, T.; Ogumi, Z. Suppression of dendritic lithium formation by using concentrated electrolyte solutions. Electrochem. Commun. 2008, 10 (4), 635-638.

(14) Ma, Q.; Qi, X. G.; Tong, B.; Zheng, Y. H.; Feng, W. F.; Nie, J.; Hu, Y. S.; Li, H.; Huang, X. J.; Chen, L. Q.; et al. Novel li[(cf3so2)(nc4f9so2)n]-based polymer electrolytes for solid-state lithium batteries with superior electrochemical performance. ACS Appl. Mater. Interfaces 2016, 8 (43), 29705-29712.

(15) Liu, M.; Zhou, D.; He, Y. B.; Fu, Y. Z.; Qin, X. Y.; Miao, C.; Du, H. D.; Li, B. H.; Yang, Q. H.; Lin, Z. Q.; et al. Novel gel polymer electrolyte for high-performance lithium-sulfur batteries. Nano Energy 2016, 22, 278-289.

(16) Miao, R. R.; Yang, J.; Xu, Z. X.; Wang, J. L.; Nuli, Y.; Sun, L. M. A new ether-based electrolyte for dendrite-free lithium-metal based rechargeable batteries. Sci. Rep. 2016, 6, DOI: 10.1038/srep21771.

(17) Nie, M. Y.; Abraham, D. P.; Seo, D. M.; Chen, Y. J.; Bose, A.; Lucht, B. L. Role of solution structure in solid electrolyte lnterphase formation on graphite with lipf6 in propylene carbonate. J. Phys. Chem. C 2013, 117 (48), 25381-25389.

(18) Yoon, T.; Chapman, N.; Seo, D. M.; Lucht, B. L. Lithium salt effects on silicon electrode performance and solid electrolyte interphase (sei) structure, role of solution structure on sei formation. J. Electrochem. Soc. 2017, 164 (9), A2082-A2088.

(19) Niehoff, P.; Passerini, S.; Winter, M. Interface investigations of a commercial lithium ion battery graphite anode material by sputter depth profile $\mathrm{x}$-ray photoelectron spectroscopy. Langmuir 2013, 29 (19), 5806-5816.

(20) $\mathrm{Xu}, \mathrm{K}$.; von Cresce, A. Interfacing electrolytes with electrodes in li ion batteries. J. Mater. Chem. 2011, 21 (27), 9849-9864.

(21) Verma, P.; Maire, P.; Novak, P. A review of the features and analyses of the solid electrolyte interphase in li-ion batteries. Electrochim. Acta 2010, 55 (22), 6332-6341.

(22) Yamada, Y.; Furukawa, K.; Sodeyama, K.; Kikuchi, K.; Yaegashi, M.; Tateyama, Y.; Yamada, A. Unusual stability of acetonitrile-based superconcentrated electrolytes for fast-charging lithium-ion batteries. J. Am. Chem. Soc. 2014, 136 (13), 5039-5046.

(23) Wang, D. Y.; Burns, J. C.; Dahn, J. R. A systematic study of the concentration of lithium hexafluorophosphate (lipf6) as a salt for licoo2/graphite pouch cells. J. Electrochem. Soc. 2014, 161 (9), A1278-A1283.

(24) Lundgren, H.; Scheers, J.; Behm, M.; Lindbergh, G. Characterization of the mass-transport phenomena in a super- concentrated litfsi:Acetonitrile electrolyte. J. Electrochem. Soc. 2015, 162 (7), A1334-A1340.

(25) Maeda, S.; Kameda, Y.; Amo, Y.; Usuki, T.; Ikeda, K.; Otomo, T.; Yanagisawa, M.; Seki, S.; Arai, N.; Watanabe, H.; et al. Local structure of li+ in concentrated ethylene carbonate solutions studied by low-frequency raman scattering and neutron diffraction with li-6/ li-7 isotopic substitution methods. J. Phys. Chem. B 2017, 121 (48), 10979-10987.

(26) McOwen, D. W.; Seo, D. M.; Borodin, O.; Vatamanu, J.; Boyle, P. D.; Henderson, W. A. Concentrated electrolytes: Decrypting electrolyte properties and reassessing al corrosion mechanisms. Energy Environ. Sci. 2014, 7 (1), 416-426.

(27) Yang, L.; Ravdel, B.; Lucht, B. L. Electrolyte reactions with the surface of high voltage lini0.5mn1.5o4 cathodes for lithium-ion batteries. Electrochem. Solid-State Lett. 2010, 13 (8), A95-A97.

(28) MacNeil, D. D.; Lu, Z. H.; Chen, Z. H.; Dahn, J. R. A comparison of the electrode/electrolyte reaction at elevated temperatures for various li-ion battery cathodes. J. Power Sources 2002, 108 $(1-2), 8-14$.

(29) Hu, L. B.; Zhang, Z. C.; Amine, K. Electrochemical investigation of carbonate-based electrolytes for high voltage lithium-ion cells. J. Power Sources 2013, 236, 175-180.

(30) Suo, L. M.; Borodin, O.; Gao, T.; Olguin, M.; Ho, J.; Fan, X. L.; Luo, C.; Wang, C. S.; Xu, K. "Water-in-salt" electrolyte enables highvoltage aqueous lithium-ion chemistries. Science 2015, 350 (6263), 938-943.

(31) Brouillette, D.; Irish, D. E.; Taylor, N. J.; Perron, G.; Odziemkowski, M.; Desnoyers, J. E. Stable solvates in solution of lithium bis(trifluoromethylsulfone)imide in glymes and other aprotic solvents: Phase diagrams, crystallography and raman spectroscopy. Phys. Chem. Chem. Phys. 2002, 4 (24), 6063-6071.

(32) Sogawa, M.; Sawayama, S.; Han, J.; Satou, C.; Ohara, K.; Matsugami, M.; Mimura, H.; Morita, M.; Fujii, K. Role of solvent size in ordered ionic structure formation in concentrated electrolytes for lithium-ion batteries. J. Phys. Chem. C 2019, 123 (14), 8699-8708.

(33) Han, S. D.; Borodin, O.; Seo, D. M.; Zhou, Z. B.; Henderson, W. A. Electrolyte solvation and ionic association v. Acetonitrilelithium bis(fluorosulfonyl)imide (lifsi) mixtures. J. Electrochem. Soc. 2014, 161 (14), A2042-A2053.

(34) Mynam, M.; Ravikumar, B.; Rai, B. Molecular dynamics study of propylene carbonate based concentrated electrolyte solutions for lithium ion batteries. J. Mol. Liq. 2019, 278, 97-104.

(35) Henderson, W. A.; Brooks, N. R.; Brennessel, W. W.; Young, V. G. Liclo4 electrolyte solvate structures. J. Phys. Chem. A 2004, 108 (1), 225-229.

(36) Han, S. D.; Allen, J. L.; Jonsson, E.; Johansson, P.; McOwen, D. W.; Boyle, P. D.; Henderson, W. A. Solvate structures and computational/spectroscopic characterization of lithium difluoro(oxalato)borate (lidfob) electrolytes. J. Phys. Chem. C 2013, 117 (11), 5521-5531.

(37) Han, S. D.; Yun, S. H.; Borodin, O.; Seo, D. M.; Sommer, R. D.; Young, V. G.; Henderson, W. A. Solvate structures and computational/spectroscopic characterization of lipf6 electrolytes. J. Phys. Chem. C 2015, 119 (16), 8492-8500.

(38) Seo, D. M.; Boyle, P. D.; Allen, J. L.; Han, S. D.; Jonsson, E.; Johansson, P.; Henderson, W. A. Solvate structures and computational/spectroscopic characterization of libf4 electrolytes. J. Phys. Chem. C 2014, 118 (32), 18377-18386.

(39) Afroz, T.; Seo, D. M.; Han, S. D.; Boyle, P. D.; Henderson, W. A. Structural interactions within lithium salt solvates: Acyclic carbonates and esters. J. Phys. Chem. C 2015, 119 (13), 7022-7027.

(40) Seo, D. M.; Afroz, T.; Allen, J. L.; Boyle, P. D.; Trulove, P. C.; De Long, H. C.; Henderson, W. A. Structural interactions within lithium salt solvates: Cyclic carbonates and esters. J. Phys. Chem. C 2014, 118 (45), 25884-25889.

(41) Seo, D. M.; Boyle, P. D.; Sommer, R. D.; Daubert, J. S.; Borodin, O.; Henderson, W. A. Solvate structures and spectroscopic characterization of litfsi electrolytes. J. Phys. Chem. B 2014, 118 (47), 13601-13608. 
(42) Ueno, K.; Tatara, R.; Tsuzuki, S.; Saito, S.; Doi, H.; Yoshida, K.; Mandai, T.; Matsugami, M.; Umebayashi, Y.; Dokko, K.; et al. Li+ solvation in glyme-li salt solvate ionic liquids. Phys. Chem. Chem. Phys. 2015, 17 (12), 8248-8257.

(43) Ueno, K.; Yoshida, K.; Tsuchiya, M.; Tachikawa, N.; Dokko, K.; Watanabe, M. Glyme-lithium salt equimolar molten mixtures: Concentrated solutions or solvate ionic liquids? J. Phys. Chem. B 2012, 116 (36), 11323-11331.

(44) Fulfer, K. D.; Kuroda, D. G. Solvation structure and dynamics of the lithium ion in organic carbonate-based electrolytes: A timedependent infrared spectroscopy study. J. Phys. Chem. C 2016, 120 (42), 24011-24022.

(45) Fulfer, K. D.; Kuroda, D. G. A comparison of the solvation structure and dynamics of the lithium ion in linear organic carbonates with different alkyl chain lengths. Phys. Chem. Chem. Phys. 2017, 19 (36), 25140-25150.

(46) Fulfer, K. D.; Kuroda, D. G. Ion speciation of lithium hexafluorophosphate in dimethyl carbonate solutions: An infrared spectroscopy study. Phys. Chem. Chem. Phys. 2018, 20 (35), 2271022718.

(47) Seo, D. M.; Reininger, S.; Kutcher, M.; Redmond, K.; Euler, W. B.; Lucht, B. L. Role of mixed solvation and ion pairing in the solution structure of lithium ion battery electrolytes. J. Phys. Chem. C 2015, 119 (25), 14038-14046.

(48) Takeuchi, M.; Matubayasi, N.; Kameda, Y.; Minofar, B.; Ishiguro, S.; Umebayashi, Y. Free-energy and structural analysis of ion solvation and contact ion-pair formation of li+ with bf4- and pf6- in water and carbonate solvents. J. Phys. Chem. B 2012, 116 (22), 64766487.

(49) Bogle, X.; Vazquez, R.; Greenbaum, S.; Cresce, A. V.; Xu, K. Understanding li+-solvent interaction in nonaqueous carbonate electrolytes with o-17 nmr. J. Phys. Chem. Lett. 2013, 4 (10), 1664-1668.

(50) Burba, C. M.; Frech, R. Spectroscopic measurements of ionic association in solutions of lipf6. J. Phys. Chem. B 2005, 109 (31), 15161-15164.

(51) Hamm, P.; Zanni, M. Concepts and methods of $2 D$ infrared spectroscopy; Cambridge University Press: Cambridge, 2011.

(52) Galle Kankanamge, S. R.; Kuroda, D. G. Molecular structure and ultrafast dynamics of sodium thiocyanate ion pairs formed in glymes of different lengths. Phys. Chem. Chem. Phys. 2019, 21 (2), 833-841.

(53) Kim, Y. S.; Wang, J. P.; Hochstrasser, R. M. Two-dimensional infrared spectroscopy of the alanine dipeptide in aqueous solution. $J$. Phys. Chem. B 2005, 109 (15), 7511-7521.

(54) Frisch, M. J.; Trucks, G. W.; Schlegel, H. B.; Scuseria, G. E.; Robb, M. A.; Cheeseman, J. R.; Scalmani, G.; Barone, V.; Mennucci, B.; Petersson, G. A.; et al. Gaussian 09, revision b.01; Gaussian Inc.: Wallingford, CT, 2009.

(55) Case, D. A.; Betz, R. M.; Cerutti, D. S.; Cheatham, T. E., III; Duke, R. E.; Giese, T.; Gohlke, H.; Goetz, A. W.; Homeyer, N.; et al. Amber 2016; University of California: San Francisco, CA, 2016.

(56) Sprenger, K. G.; Jaeger, V. W.; Pfaendtner, J. The general amber force field (gaff) can accurately predict thermodynamic and transport properties of many ionic liquids. J. Phys. Chem. B 2015, 119 (18), 5882-5895.

(57) Kumar, N.; Seminario, J. M. Lithium-ion model behavior in an ethylene carbonate electrolyte using molecular dynamics. J. Phys. Chem. C 2016, 120 (30), 16322-16332.

(58) Barthel, J.; Buchner, R.; Wismeth, E. Ftir spectroscopy of ion solvation of liclo4 and liscn in acetonitrile, benzonitrile, and propylene carbonate. J. Solution Chem. 2000, 29 (10), 937-954.

(59) Aroca, R.; Nazri, R.; Nazri, G. A.; Camargo, A. J.; Trsic, M. Vibrational spectra and ion-pair properties of lithium hexafluorophosphate in ethylene carbonate based mixed-solvent systems for lithium batteries. J. Solution Chem. 2000, 29 (10), 1047-1060.

(60) Amunson, K. E.; Kubelka, J. On the temperature dependence of amide i frequencies of peptides in solution. J. Phys. Chem. B 2007, 111 (33), 9993-9998.
(61) Rushing, J. C.; Leonik, F. M.; Kuroda, D. G. Effect of solvation shell structure and composition on ion pair formation: The case study of litdi in organic carbonates. J. Phys. Chem. C 2019, 123 (41), 25102-25112.

(62) Bhatt, M. D.; Cho, M.; Cho, K. Interaction of li+ ions with ethylene carbonate (ec): Density functional theory calculations. Appl. Surf. Sci. 2010, 257 (5), 1463-1468.

(63) Ding, W. H.; Lei, X. L.; Ouyang, C. Y. Coordination of lithium ion with ethylene carbonate electrolyte solvent: A computational study. Int. J. Quantum Chem. 2016, 116 (2), 97-102.

(64) Li, T.; Balbuena, P. B. Theoretical studies of lithium perchlorate in ethylene carbonate, propylene carbonate, and their mixtures. J. Electrochem. Soc. 1999, 146 (10), 3613-3622.

(65) Hyodo, S. A.; Okabayashi, K. Raman intensity study of localstructure in non-aqueous electrolyte-solutions 0.2. Cation solvent interaction in mixed-solvent systems and selective solvation. Electrochim. Acta 1989, 34 (11), 1557-1561.

(66) Doucey, L.; Revault, M.; Lautie, A.; Chausse, A.; Messina, R. A study of the li/li+ couple in $\mathrm{dmc}$ and $\mathrm{pc}$ solvents - part 1 : Characterization of liasf6/dmc and liasf6/pc solutions. Electrochim. Acta 1999, 44 (14), 2371-2377.

(67) Kameda, Y.; Umebayashi, Y.; Takeuchi, M.; Wahab, M. A.; Fukuda, S.; Ishiguro, S. I.; Sasaki, M.; Amo, Y.; Usuki, T. Solvation structure of li+ in concentrated lipf6-propylene carbonate solutions. J. Phys. Chem. B 2007, 111 (22), 6104-6109.

(68) Morita, M.; Asai, Y.; Yoshimoto, N.; Ishikawa, M. A raman spectroscopic study of organic electrolyte solutions based on binary solvent systems of ethylene carbonate with low viscosity solvents which dissolve different lithium salts. J. Chem. Soc., Faraday Trans. 1998, 94 (23), 3451-3456.

(69) Zhang, X. L.; Kuroda, D. G. An ab initio molecular dynamics study of the solvation structure and ultrafast dynamics of lithium salts in organic carbonates: A comparison between linear and cyclic carbonates. J. Chem. Phys. 2019, 150 (18), 184501.

(70) Tasaki, K.; Goldberg, A.; Liang, J.-J.; Winter, M. New insight into electrochemical differences in cycling behaviors of a lithium-ion battery cell between the ethylene carbonate- and propylene carbonatebased electrolytes. MRS Proceedings 2011, 1313, mrsf10.

(71) Yuan, K. J.; Bian, H. T.; Shen, Y. N.; Jiang, B.; Li, J. B.; Zhang, Y. F.; Chen, H. L.; Zheng, J. R. Coordination number of lit in nonaqueous electrolyte solutions determined by molecular rotational measurements. J. Phys. Chem. B 2014, 118 (13), 3689-3695.

(72) Borodin, O.; Smith, G. D. Litfsi structure and transport in ethylene carbonate from molecular dynamics simulations. J. Phys. Chem. B 2006, 110 (10), 4971-4977.

(73) Borodin, O.; Smith, G. D. Quantum chemistry and molecular dynamics simulation study of dimethyl carbonate: Ethylene carbonate electrolytes doped with lipf6. J. Phys. Chem. B 2009, 113 (6), 17631776.

(74) Ong, M. T.; Verners, O.; Draeger, E. W.; van Duin, A. C. T.; Lordi, V.; Pask, J. E. Lithium ion solvation and diffusion in bulk organic electrolytes from first-principles and classical reactive molecular dynamics. J. Phys. Chem. B 2015, 119 (4), 1535-1545.

(75) Lee, K. K.; Park, K.; Lee, H. C.; Noh, Y. H.; Kossowska, D.; Kwak, K.; Cho, M. Ultrafast fluxional exchange dynamics in electrolyte solvation sheath of lithium ion battery. Nat. Commun. 2017, 8, DOI: $10.1038 /$ ncomms 14658 .

(76) Jiang, B.; Ponnuchamy, V.; Shen, Y. N.; Yang, X. M.; Yuan, K. J.; Vetere, V.; Mossa, S.; Skarmoutsos, I.; Zhang, Y. F.; Zheng, J. R. The anion effect on lit ion coordination structure in ethylene carbonate solutions. J. Phys. Chem. Lett. 2016, 7 (18), 3554-3559.

(77) Borodin, O.; Suo, L. M.; Gobet, M.; Ren, X. M.; Wang, F.; Faraone, A.; Peng, J.; Olguin, M.; Schroeder, M.; Ding, M. S.; et al. Liquid structure with nano-heterogeneity promotes cationic transport in concentrated electrolytes. ACS Nano 2017, 11 (10), 10462-10471.

(78) Kondou, S.; Thomas, M. L.; Mandai, T.; Ueno, K.; Dokko, K.; Watanabe, M. Ionic transport in highly concentrated lithium bis(fluorosulfonyl)amide electrolytes with keto ester solvents: 
Structural implications for ion hopping conduction in liquid electrolytes. Phys. Chem. Chem. Phys. 2019, 21 (9), 5097-5105.

(79) Tagawa, A.; Numata, T.; Shikata, T. Anti-parallel dimer and tetramer formation of propylene carbonate. AIP Adv. 2017, 7 (9), 095103.

(80) Bohets, H.; van der Veken, B. J. On the conformational behavior of dimethyl carbonate. Phys. Chem. Chem. Phys. 1999, 1 (8), $1817-1826$.

(81) Gontrani, L.; Russina, O.; Marincola, F. C.; Caminiti, R. An energy dispersive $\mathrm{x}$-ray scattering and molecular dynamics study of liquid dimethyl carbonate. J. Chem. Phys. 2009, 131 (24), 244503.

(82) Kwac, K.; Cho, M. H. Molecular dynamics simulation study of n-methylacetamide in water. Ii. Two-dimensional infrared pumpprobe spectra. J. Chem. Phys. 2003, 119 (4), 2256-2263.

(83) Kar, B. P.; Ramanathan, N.; Sundararajan, K.; Viswanathan, K. S. Conformations of dimethyl carbonate and its complexes with water: A matrix isolation infrared and ab initio study. J. Mol. Struct. 2012, 1024, 84-93.

(84) Golonzka, O.; Khalil, M.; Demirdoven, N.; Tokmakoff, A. Coupling and orientation between anharmonic vibrations characterized with two-dimensional infrared vibrational echo spectroscopy. J. Chem. Phys. 2001, 115 (23), 10814-10828.

(85) Kim, Y. S.; Hochstrasser, R. M. Chemical exchange $2 \mathrm{~d}$ ir of hydrogen-bond making and breaking. Proc. Natl. Acad. Sci. U. S. A. 2005, 102 (32), 11185-11190.

(86) Herstedt, M.; Smirnov, M.; Johansson, P.; Chami, M.; Grondin, J.; Servant, L.; Lassegues, J. C. Spectroscopic characterization of the conformational states of the bis (trifluoromethanesulfonyl)imide anion (tfsi-). J. Raman Spectrosc. 2005, 36 (8), 762-770.

(87) Johansson, P.; Gejji, S. P.; Tegenfeldt, J.; Lindgren, J. The imide ion: Potential energy surface and geometries. Electrochim. Acta 1998, 43 (10-11), 1375-1379.

(88) Lassegues, J. C.; Grondin, J.; Aupetit, C.; Johansson, P. Spectroscopic identification of the lithium ion transporting species in litfsi-doped ionic liquids. J. Phys. Chem. A 2009, 113 (1), 305-314.

(89) Taylor, R. Interpretation of the correlation-coefficient - a basic review. J. Diagn. Med. Sonog. 1990, 6 (1), 35-39.

(90) Hanggi, P.; Talkner, P.; Borkovec, M. Reaction-rate theory - 50 years after kramers. Rev. Mod. Phys. 1990, 62 (2), 251-341.

(91) Laage, D.; Hynes, J. T. On the residence time for water in a solute hydration shell: Application to aqueous halide solutions. J. Phys. Chem. B 2008, 112 (26), 7697-7701.

(92) Dokko, K.; Watanabe, D.; Ugata, Y.; Thomas, M. L.; Tsuzuki, S.; Shinoda, W.; Hashimoto, K.; Ueno, K.; Umebayashi, Y.; Watanabe, M. Direct evidence for li ion hopping conduction in highly concentrated sulfolane-based liquid electrolytes. J. Phys. Chem. B 2018, 122 (47), 10736-10745.

(93) Ugata, Y.; Thomas, M. L.; Mandai, T.; Ueno, K.; Dokko, K.; Watanabe, M. Li-ion hopping conduction in highly concentrated lithium bis(fluorosulfonyl)amide/dinitrile liquid electrolytes. Phys. Chem. Chem. Phys. 2019, 21 (19), 9759-9768.

(94) Kankanamge, S. R. G.; Li, K.; Fulfer, K. D.; Du, P.; Jorn, R.; Kumar, R.; Kuroda, D. G. Mechanism behind the unusually high conductivities of high concentrated sodium ion glyme-based electrolytes. J. Phys. Chem. C 2018, 122 (44), 25237-25246. 